\title{
Ethics, Efficacy, and Decision-making in Animal Research
}

\author{
Lawrence A. Hansen \\ Professor of Pathology, University of California, San Diego, United States
}

Kori Ann Kosberg

University of California, San Diego, United States

kosberg@me.com

\section{Introduction}

The true rule in determining to embrace or reject anything is not whether it has any good in it, but whether it has more of evil than of good. Few things are wholly evil or wholly good. Almost everything is a composite of the two, so that our best judgement of the predominance between them is continually demanded.

ABRAHAM LINCOLN, June 20, 1848, in a speech to the United States (Us) House of Representatives on Internal Improvements, suggesting an approach to decision making in ethically complex situations

Few would disagree with the ethical contention that if cruelty to animals is not wrong, then nothing is wrong. In fact, it is not only wrong, but in most states in the Us, it is a crime, a felony no less. And yet, intentionally inflicting pain and suffering upon animals, which meets Webster's definition of cruelty, is routinely countenanced when vivisection (from the Latin vivi, to be alive, and secare, to cut) is performed under license for biomedical research. Deciding to embrace, or reject, or limit animal research demands our best ethical judgment; and it is complicated by factual disputes over the extent to which it benefits human health. Three issues combining facts and ethics need to be considered. First, to what extent does animal research deliver on its promise to improve human health? Second, if the goal of public investment (e.g., tax dollars spent by the National Institute of Health, $\mathrm{NIH}$ ) on animal research is to improve human health, are we getting sufficient return for the billions spent, 
or might the money be better directed towards human-based research or implementing healthcare interventions of proven efficacy? Third, since opinions about ends justifying means will vary, who should decide if animal research is ethically justified: the scientists who perform it or representatives of the public at large, who pay for it?

In the Us, the biomedical academic research establishment, as currently constituted, empowers animal researchers to determine what animal experimentation is allowed. But this represents an obvious conflict of interest, since the researchers' livelihoods depend on continuing animal use, and their attitudes about the ethical justifications for vivisection are a priori set in stone, as evidenced by their career choices. Shifting the ethical paradigm about animal experimentation will require transferring decision-making authority about animal use in science from the animal researchers who carrying out experiments to the public who finances them and who may be less inclined to approve any and all use of animals in experimentation.

\section{To What Extent Does Animal Research Improve Human Health?}

It is axiomatic, even reflexive, for proponents of animal research to contend that virtually every medical achievement of the last century has depended directly or indirectly on research with animals. But it may be wise to consider the source of such a sweeping proclamation. The quotation traces back to a 1994 article in The Physiologist, a journal heavily invested in publishing animal research, entitled "The importance of animals in biomedical and behavioral research" where it appears as a bold assertion unaccompanied by any substantiating evidence (Matthews, 2008, p. 95). Does this claim bear up under empirical scrutiny in the modern era of evidence-based medicine?

A recently published summary of systematic reviews investigating the relevance of animal based research to human medicine (Pound and Bracken, 2014) provides a comprehensive consideration of the topic. The authors conclude that animal research is plagued by poor quality, typically fails to address internal and external validity, lacks randomization and blinding, engages in selective analysis and outcome reporting, and suffers from publication bias, all resulting in overstatements about the validity of entire bodies of research. An even more exhaustively referenced review article on the use of animals in medical science research cites multiple studies documenting the failure of animal models to translate into human benefit in HIV/AIDS, stroke, cancer, spinal cord injury, traumatic brain injury, cardiovascular disease, diabetes, and menopausal hormonal therapy (Pippin, 2013). A prescient earlier analysis by Crowley in 2003 (Sung et al., 2003) had already established that out that of 25,000 basic 
research articles published in the top 6-ranked journals for basic research, only one was associated with a clinically useful new drug in 30 years of publication. The dismal track record of animal research leading to improved human health has been succinctly summarized in yet another study (Tsilidis et al., 2013) reviewing data from the Collaborative Approach to Meta-Analysis and Review of Animal Data from Experimental Studies, which concludes that bias in animal studies makes it nearly impossible to rely on most animal data to predict whether or not an intervention will have a favorable clinical benefit-risk ratio in human subjects.

Poor study design contaminated by bias doubtlessly contributes to the irrelevance of most animal research to medical progress. But a deeper, fatal flaw in the entire animal research paradigm may be its assumption that evolutionary continuity between humans and other animals allows valid cross-species extrapolation, essentially a presupposition that what we learn to be true in one species will be true in another (Ioannidis, 2012). Evolutionary continuity can account for the success of animal model extrapolations early in the history of physiology, as when William Harvey, a seminal figure in the development of medicine and physiology, correctly deduced the closed-circuit nature of human blood flow after observing it in non-human animals. But that was in 1628; in the modern era of personalized medicine, when patients' tumors are characterized with chromosomal scanning and cancer gene panels to identify specific mutations directing individualized chemotherapy, the notion that mice represent furry pocket-sized models of humans seems scientifically quaint. Non-human animals are not simplified versions of humans, as the word model implies, but are rather evolved systems, differently complex in their own right. Small differences in initial conditions of a complex system, such as diverging regulation and expression of genes, modifier genes, or posttranslational protein processing can result in two superficially similar systems (human and non-human animals), exhibiting vastly different responses to the same experimental manipulations (Greek and Shanks, 2009).

If forced to concede by meta-analyses that most animal experimentation bears no clinical fruit, animal researchers defend it by arguing that its critics are insufficiently appreciative of the contributions made by vivisection to our cumulative fund of biomedical knowledge (Carbone, 2012), not only as a curiosity-driven, fact-finding quest for knowledge, but as it applies to the understanding and progression of human disease. This argument justifies animal research as basic rather than applied science. How can opponents of animal research ever know that in the fullness of time an insight into basic biology derived from an animal experiment of no relevance to human health, at the time it was performed, might not, someday, be important to improving health? This rhetorical contention is nebulous enough to be impossible to refute, since 
no one knows the future. Any and all research is justified by this argument, and it implies that no ethical balancing of pain and suffering cost to experimental animals against the expectation of human health gain should even be attempted. Basic research that uses animals will continue to find new facts about basic biology, as it has in the past. But to conflate finding new facts with advances in human health as ethical justification for animal research is a disingenuous bait and switch.

\section{3 \\ What Is the Cost to Benefit Ratio of Spending on Animal Research to Improve Health?}

Dawning awareness of the failure of most animal based research to benefit human health is reflected in commentary from the current and a former head of the $\mathrm{NIH}$, the agency in charge of funding biomedical research in the Us, with a U $\$ 39$ billion budget in 2019 (NIH, 2019). Francis Collins, the present head of the NIH, wrote, "The use of animal models for therapeutic development and target validation is time consuming, costly, and may not accurately predict efficacy in humans. As a result, many clinical compounds are carried forward only to fail in phase II or phase III clinical trials: many others are probably abandoned because of the shortcomings of the [animal] model" (Collins, 2011, p. 3). Concerning the same failure of animal models, a former NIH director, Elias Zerhouni, commented more memorably, "We have moved away from studying human disease in humans. We all drank the Kool-Aid on that one [transgenic mouse models], me included [...] The problem is that it hasn't worked, and it's time we stopped dancing around the problem [...] We need to refocus and adapt new methodologies for use in humans to understand disease biology in humans" (McManus, 2013).

Among such innovative new methodologies for studying human diseases in humans are organotypic cultures that combine cellular constituents to replicate entire tissues and tumor environments, allowing cellular, subcellular, and molecular biological experiments historically performed on animals to instead be conducted on the species of interest - humans. Bacterial production of insulin has replaced its traditional extraction from bovine or swine pancreas, and chromatography is used to determine drug purity and dosage rather than animal usage (Doke and Dhawale, 2015). Human stem cells are another modern research modality being utilized to study human diseases and develop drugs to combat them. Experimental techniques converging on the goal of personalized medicine include pharmacogenomics and genetic (gene chip) microarrays. These wet bench innovations are complimented by advanced non-invasive imaging methods, such as positron emission tomography, 
accelerator mass spectroscopy, and magnetic resonance imaging. These and many other human-species relevant research methods may be far more likely than discredited animal models to advance health.

Proponents of animal research often invoke the ultimate goal of reducing human disease morbidity and mortality as justification for the pain and suffering inherent in animal experimentation. In truth, however, if that is the goal, then from a global health perspective, we would be getting a much better return on healthcare investment by sparing the animals and spending the money on soap and hand-washing. Every year, respiratory infections and diarrhea kill more than 3.5 million children under the age of 5 , and that death toll could be cut in half simply with soap and hand-washing. One study found $50 \%$ less pneumonia and $53 \%$ fewer cases of diarrhea in families given soap and encouraged to wash their hands (Luby et al., 2005). A meta-analysis of similar studies of diarrhea alone concluded that hand washing reduced its incidence by $42 \%-$ $47 \%$, and that promoting hand washing could save a million lives a year (Curtis and Carincross, 2003). No one expects the us research establishment to redirect any of its funding toward hand washing in the cause of global healthcare or health justice, since the lives to be saved are outside the us. Nevertheless, ethical justification for animal research, as a means for improving human health, should be viewed with some skepticism when far more directly effective, less expensive, and ethically unproblematic means for saving millions of children's lives are immediately at hand but underutilized because of spending priorities.

Stewardship is the careful and responsible management of something entrusted to one's care. The concept has Judeo-Christian roots but has acquired a secular meaning in an environmental context, embraced by many with no religious faith at all. Originally, stewardship was an obligation imposed upon humankind by God, when granting humanity dominion over the rest of creation. As is often the case with the exercise of power, this dominion of humans over animals has not worked to the animals' advantage. For millennia, the prevailing human ethos has been instrumentalism, the belief that animals exist for us, to serve our interests and wants. This attitude stems from moral anthropocentrism, the conviction that humans, set above animals by divine edict, should always have absolute priority in our moral reasoning about animal use. While this Judeo-Christian tradition has been hard on animals, at least in theory, obligations of stewardship accompanying dominion should temper our treatment of animals even as we use them for our own ends. 
The concept of stewardship persists in altered form, as society has become progressively less religious and more secular, challenging traditional assumptions about humanity's divinely ordained special status in creation. The fact of human dominion remains, even if attributed to evolutionary happenstance, and is recognized in an atheist scientific worldview, now often expressed by the term homocene or anthropocene to describe a human dominated natural world (Schwagerl and Crutzen, 2014). A secularized version of stewardship endures too, transformed into an ethical environmentalism in which our obligation is to preserve the ecological habitability of the planet we inherited for future generations to enjoy. One ramification of ecological rather than religious stewardship is the recognition that humans are part of rather than over and above the rest of nature. As Darwin initially observed, and subsequent evolutionary biology has confirmed, human and non-human animals are fundamentally more alike than dissimilar (Darwin, 1859). Beyond shared biology, behavioral research shows that many animals exhibit traits once presumed to be uniquely human, including sympathy, empathy, cooperation, a sense of fairness and justice, and a very humanlike capacity for future oriented cognition (Roberts, 2012). The privileged moral status humans continue to assign ourselves is ethically arbitrary and self-serving, more an example of humans as rationalizing than rational creatures, enlisting our intellectual nimbleness in the service of our desires.

Animal researchers should consider themselves doubly obligated by a contemporary secular sense of stewardship. First, society pays for what they do; and the poor translation of most animal research into human health benefits, which is what the public thinks that it is buying, is a failure of financial stewardship. Second, stewardship in a secular scientific age requires a rebalancing of the ethical scales we use in determining what kind of animal use is justifiable. Science informs us that animals are sentient beings like ourselves, capable of pleasure and pain (Griffin and Speck, 2004). They are not just property or tools; they have their own interior life deserving of respect. If a more highly sophisticated capacity for ethical reasoning and morality is what sets humans apart from other animals, then ethical reasoning and morality must always guide us in how we treat them. Cruel basic science, rather than medically relevant experiments performed on empathy-inspiring species, may seem to be the easy case to make against animal research as poor ethical stewardship. Nevertheless, decades of protests, focused on such seemingly easy cases to make, have not, for example, stopped neurophysiological visual tracking research on Rhesus macaques in which they undergo coil implants in both eyes, holes drilled into their skulls for recording electrode placements, and head immobilization surgeries in which screws, plates, and bolts are implanted in their heads. 
Following these procedures, the monkeys are dehydrated to provide, what the researchers call, a "work ethic", so that they will visually track a moving object for a sip of water reward, while tied into a restraining chair with their heads bolted into an immobilizing frame. First impressions are accurate in recognizing animal cruelty, and most of us cannot even bear to look at pictures of these monkeys with bolted heads and electrode-implanted brains being put through their paces in a desperate attempt to get a life sustaining sip of water; but despite ethical revulsion to an easy case of animal cruelty, this research has continued for decades (Ramachandran and Lisberger, 2005); and cats, another favored species, are being treated similarly (Yartsev, 2009), as well as mice (Guo et al., 2014). Making animals suffer this intensely, in pursuit of a basic science research agenda, merely because we can, because we have the power of total control over them, is more despotism than stewardship. "Might makes right" is not an ethical argument.

Who Decides if Ends Justify Means in the Ethics of Animal Research?

Animal researchers occupy one end of an ethical opinion spectrum. They have concluded that the hypothetical expanding of scientific knowledge justifies the means they employ, and that the suffering inflicted on experimental animals is acceptable in the pursuit of a greater good. At the opposite pole are animal rights activists, who believe that cruelty to animals is wrong, period, and that no scientific ends can justify means that entail animal pain and suffering. Public opinion polling informs us that most people occupy an ethical middle ground, with approval of animal research contingent upon animals not suffering too much, and only in the service of research likely to benefit human health. $51 \%$ of Americans believe medical testing on animals is morally acceptable (Jones, 2017); and $65 \%$ of the United Kingdom public supports medical testing in the absence of an alternative model (Clemence and Leaman, 2016). People also express different attitudes towards animal use, depending on the species involved, and are less supportive of research using dogs, cats, and non-human primates than of research with mice, rats, and fish (Ormandy and Schuppli, 2014). $48 \%$ of people in the UK believe it is acceptable to use rats in medical research to benefit people, while only $16 \%$ approve of using dogs (Clemence and Leaman, 2016). So, how are these ethical differences arbitrated in academic research centers at present? And who gets to decide, in specific instances of proposed animal use, if the end justifies the means? 
In the us, federal laws and regulations that govern animal use in research stem from public outrage over cruelty to animals destined for research laboratories exposed in a LIFE magazine article in 1966, which prompted the Us Congress to pass the Laboratory Animal Welfare Act. Subsequently renamed the Animal Welfare Act (AWA), and repeatedly amended in the decades since, it is administered by the Department of Agriculture (USDA). A 1985 AWA amendment and the Health Research Extension Act, also passed in 1985 and administered under Public Health Service (PHS) Policy on Humane Care and Use of Laboratory Animals rules, both mandated the establishment of Institutional Animal Care and Use Committees (IACUCs) at all facilities performing biomedical research on animals (Levin and Reppy, 2015). Minimum IACUC membership requirements, initially set forth in the AwA, balanced public bioethical concerns and scientific expertise, stipulating a three-member committee to include a laboratory animal veterinarian, a committee chair, and one member who is not affiliated in any way with the institution and is not an animal user, who would represent general community interests in the treatment of animals. The minimum PHS IACUC requirements were similarly balanced, stipulating a minimum of five persons, including an institutional laboratory veterinarian, an animal researcher, a member unaffiliated with the institution, and a member whose primary concern was not in the scientific arena (e.g., an ethicist, lawyer, or clergy member) (Hansen, 2013).

The founding directives for IACUC memberships would have created IACUCS that reflected public concern for laboratory animal welfare and performed ethical cost-benefit analyses of proposed animal research, with approval contingent upon a balancing of animal pain and suffering against a reasonable expectation of resultant human benefit. However, institutions heavily incentivized by grant funding attached to animal research realized that the USDA and PHS dictates for IACUC membership were only minimum requirements which did not limit the numbers of additional animal researchers who could be appointed to the committees, tipping their balance to ensure approval of all animal research protocols. They also recognized that, unlike the European Union Directive instituted to address the same bioethical issues in animal research (Directive 2010/63/EU, European Parliament, 2010), neither of the two US regulatory requirements set for IACUCS specifically mandated an ethical review of animal research protocols prior to their authorization (Levin and Reppy, 2015).

Consequently, expanded IACUCs now averaging 23 members rather than three or five, are heavily skewed towards animal researchers $(67 \%)$ and institutional veterinarians whose livelihoods depend on animal research $(15 \%)$, and $93 \%$ of IACUC chairs are animal researchers (Hansen, 2013). Predictably, 
IACUCs in which $82 \%$ of members and $93 \%$ of chairs have vested interests in continuing animal research approve essentially all proposed animal experiments set before them. $98 \%$ of proposed animal experiments are approved according to the most comprehensive analysis available (Plous and Herzog, 2001), without considering an ethical balancing of animal harm against human health gain. An expert on how IACUCs function, and a longtime defender of the system, writes plainly, "Few people realize that virtually nothing is prohibited by the Animal Welfare Act, so long as it can be justified to the IACUC. Nor do IACUCs, by and large, function by rejecting animal protocols when the ethical costs are too high [...] [R] ejection of protocols is not what IACUCs do $[\ldots]$ [E]ven painful animal experiment may be allowed [...] any research protocol may be approved $[. .$.$] regardless of any weighing of the potential benefits"$ (Carbone, 2004).

This institutionalized blanket endorsement of all animal use disregards the public's attitude of contingent approval of animal research, heavily qualified by concerns over limiting suffering, promises of resultant disease treatments, and avoidance of experimentation on favored species, i.e. dogs, cats, and primates (Henry and Roarke, 2009; Swami, Furnah, and Christopher, 2008). An example IACUC ruling from the University of California, San Diego (UCSD), in 2001, illustrates how disconnected the system is from public bioethics. Hundreds of San Diego physicians signed an anti-dog lab petition, urging the Medical School to end dog vivisection and euthanasia teaching exercises in a freshman pharmacology course. These physicians knew from professional experience that killing dogs was unnecessary in becoming a doctor and so filed an appeal to the UCSD IACUC, pointing to PHS guidelines requiring a good-faith effort to replace animal labs in education and research, once alternatives became available. The signatories to the anti-dog lab petition reasoned that since $95 \%$ of schools taught the course without killing dogs (Hansen and Boss, 2002), it must be unnecessary for UCSD to do so. The official response of the UCSD IACUC was that vivisection and euthanasia of dozens of dogs in those labs raised no animal welfare issues. This seemed like Orwellian newspeak to the doctors, and public protests followed. Finally, after sufficient adverse publicity, the UCSD Faculty Council and School of Medicine Department Chairs ended the unnecessary dog vivisections, accomplishing what the IACUC should have done years before; that is, "respect society's concerns regarding the welfare of animal subjects" (Hansen, 2013, p. 188), as was stipulated in the AWA amendment of 1985 , creating the IACUC system.

So, the answer to the question, who decides if ends justify means in the ethics of animal research? is - animal researchers. But the word decide is misleading in this context, if it is taken to imply the result of a deliberative process that 
could have more than one outcome, as when a jury decides to acquit or convict a defendant. The animal researcher dominated IACUCs have determined a priori that experimental animals are of so little ethical worth compared to the value they place on hypothetically increasing scientific knowledge that the ends always justify the means. Decisions from committees of wolves arbitrating the fate of sheep would be less predictable.

\section{How Could Research Ethics Be Better Aligned with Public Concern} for Animal Welfare?

The IACUC system fails to address ethical issues in animal research which are of concern to the public, because it is dominated by those whose livelihoods, careers, and professional identities are dependent upon the unfettered continuation of animal experimentation. It is asking too much of human nature to expect that committees of animal researchers could set aside their conflicts of interest, inclination to groupthink, and conscious and unconscious biases to look at the ethics of animal use in research as does society at large. Ethical constraints on how animals are treated in research have always been externally imposed on an, oftentimes, resistant biomedical establishment. The latter's ingenuity in evading such constraints is seen not only in its stacking of the IACUC membership deck with animal researchers, but also by its successful lobbying effort to amend the AWA in 2002, so as to exclude from its protections mice and rats who comprise $99 \%$ of the animals used in research laboratories (Farm Security and Rural Investment Act, 2002). Even the few favored species of greatest ethical concern to the public, i.e. primates, dogs, and cats, supposedly covered by the nominal protections of the AWA, are routinely subject to medically irrelevant basic science experimentation, which most people would consider cruelty, if it were performed on themselves or their pet dogs or cats.

Two possible solutions to the disconnect between society's nuanced and qualified attitude towards animal research and the IACUC's philosophy of "anything goes" are worth considering, both of which would work towards achieving the paradigm shift in ending animal experimentation. First, the AWA could be amended to restore its initially intended balance between researchers and members representing societal interest in animal welfare. A second more definitive approach would be a legal ban on research using primates, dogs, and cats, leaving researchers with $99 \%$ of the animals they are using currently, and respecting the public's ethical qualms about the suffering of their favored species. One precedent for how protecting favored species may succeed is the 
constraint recently imposed on chimpanzee research by the $\mathrm{NIH}$, in response to a report from the Institute of Medicine Committee on the Necessity of the Use of Chimpanzees in Biomedical and Behavioral Research (Kahn, 2014). If one species of non-human animals can be set off limits to vivisection, solely because of ethical concerns, it raises hopes that others may follow, which is why the constraints were so strongly opposed by animal researchers not using chimpanzees, fearing this precedent may be the thin edge of an ethical wedge. As for legally banning companion animal research, the fact that in 2014 Americans spent over Us $\$ 50$ billion on their dogs and cats may indicate that there is a deep, yet untapped, reservoir of potential political support for such legislation.

Summary and Conclusions

Paradigm shifts in science occur when new theories make more accurate and reproducible predictions than old ones about empirically observed natural phenomena or experimental results. When the term paradigm shift is applied to the ethics of animal experimentation, the concept becomes less scientifically literal, and understanding how ethically seismic paradigm shifts occur in human history is challenging. Once they have occurred, however slow their incubation, they are codified into laws reflecting an altered ethical consensus. Slavery was once legal, now it is not; women now have equality under the law with men, but through most of human history they did not. Changing the ethical paradigm about animal experimentation requires both a scientific analysis of its lack of efficacy in improving human health, and an ethical appeal to broaden our sphere of compassion for ourfellow sentients. If successful, such a paradigm change will ultimately outlaw any animal experimentation that causes pain and suffering.

From a purely scientific perspective, multiple meta-analyses indicate that animal based research only rarely translates into improved human health. This failure of to benefit human health can result from poor study design as well as intrinsic evolutionary differences, precluding the extrapolation of results from one species to another; but regardless of its cause, this failure undercuts a major ethical justification for inflicting harm on animals in biomedical research. NIH directors past and present recognize the low yield of animal research in benefitting human health and recommend shifting funding priorities towards new methodologies for use in humans to understand disease biology in humans (McManus, 2013). From a global healthcare perspective, and considering the ethics of healthcare justice, money spent on basic science animal research, if diverted to implementing healthcare interventions of proven efficacy, could save many 
millions more human lives. Legal constraints were imposed on animal research by us Congress in response to public outrage over exposés of animal abuse, resulting in the Laboratory Animal Welfare Act in 1966 and the mandated creation of IACUCs in 1985 to address public concerns about laboratory animal welfare. However, IACUCS, as currently constituted, are dominated by animal researchers who have determined, a priori, to approve any and all use of animals in biomedical research, without regard to public ethical concerns about limiting animal suffering, which species are used, and relevance to human health.

Because animal researchers now control the use of animals in experimentation, any paradigm change will require wrestling authority away from them and investing it in a broader range of ethical stakeholders, specifically the public and its elected representatives who are more inclined than career vivisectors to weigh the ethical cost to human benefit of animal experimentation. The ban on chimpanzee vivisection, despite the opposition of animal experimenters, may represent a template for moral progress toward the hoped-for paradigm shift. If public empathy for our fellow primates can overcome the resistance of the biomedical academic establishment to banning chimpanzee research, it is cause for optimism that a similar approach to other favored species, such as dogs and cats, may generate an ethical momentum, like falling dominoes, towards finally expanding the circle of human compassion to encompass all creatures capable of pain and suffering.

\section{References}

Carbone, L. (2004). What Animals Want: Expertise and Advocacy in Laboratory Animal Welfare Policy. New York: Oxford University Press, pp. 186-188.

Carbone, L. (2012). The Utility of Basic Animal Research. The Hastings Center-Bioethics and Public Policy. Supplement, pp. S12-15.

Clemence, M. and J. Leaman (2016). Public Attitudes to Animal Research in 2016. A report by Ipsos MORI for the Department for Business, Energy \& Industrial Strategy, Ipsos MORI Social Research Instititute. [online] Available at: https://www. ipsos.com/sites/default/files/publication/1970-01/sri-public-attitudes-to-animalresearch-2016.pdf [Accessed 10 February 2018].

Collins, F. (2011). Reengineering Translational Science: The Time Is Right. Science Translational Medicine, 3, pp. 1-6.

Curtis, V. and S. Carincross (2003). Effect of washing hands with soap on diarrhoea risk in the community: a systematic review. The Lancet Infectious Diseases, 3, pp. $275^{-281 .}$ 
Darwin, C. (1859). On the origin of species. Create Space Independent Publishing Platform.

Doke, S. and S. Dhawale (2015). Alternatives to Animals Testing: A Review. Saudi Pharmaceutical Journal, 23, pp. 223-229.

European Parliament(2010). Directive 2010/63/EU of the European Parliamentand of the Council of 22 September 2010 on the protection of animals used for scientific purposes. Official Journal of the European Communities, L276, p. 33-79. [online] Available at: http://eur-lex.europa.eu/legal-content/EN/TXT/?uri=CELEX:32010Loo63 [Accessed 10 February 2018].

Farm Security and Rural Investment Act 2002. Public Law, 107-171 § 10301, 116 Stat. 491.

Greek, J. and N. Shanks (2009). Thoughts on Animal Models for Human Disease and Treatment. Journal of the American Veterinary Medical Association, 15, pp. 363-364.

Griffin, D.R. and G.B. Speck (2004). New Evidence of Animal Consciousness. Animal Cognition, 7 , pp. $5^{-18 .}$

Guo, Z., S. Hires, L. Nuo, D. O'Connor, T. Komiyama, E. Ophir, D. Huber, C. Bonardi, K. Morandell, D. Gutnisky, S. Peron, N. Xu, J. Cox and K. Svoboda (2014). Procedures for Behavior Experiments in Head-Fixed Mice. PLOS One, 9, p. e101397. [online] Available at: http://journals.plos.org/plosone/article?id=10.1371/journal.pone.0088678 [Accessed 10 February 2018].

Hansen, L.A. (2013). Institutional Animal Care and use Committees Need Greater Ethical Diversity. Journal of Medical Ethics, 39, pp. 188-19o.

Hansen, L.A. and G.R. Boss (2002). Use of Live Animals in the Curricula of us Medical Schools: Survey Results from 2001. Academic Medicine, 77, pp. 1147-1149.

Henry, B. and P. Roarke (2009). Individual Difference and Study-specific Characteristics Influencing Attitudes about the Use of Animals in Medical Research. Society and Animals, 17, pp. 305-324.

Ioannidis, J. (2012). Extrapolating from Animals to Humans. Science Translational Medicine, 4, pp. $151 \mathrm{ps} 15$.

Jones, J. (2017). Americans hold record liberal views on most moral issues. Social and Policy Issues. [online] Available at: http://news.gallup.com/poll/210542/americanshold-record-liberal-views-moral-issues.aspx [Accessed 10 February 2018].

Kahn, J. (2014). Lessons Learned: Challenges in Applying Current Constraints on Research on Chimpanzees to Other Animals. Theoretical Biology and Medical Modeling, 35, pp. 97-104.

Levin, L.H. and W.A. Reppy (2015). Reforming the Politics of Animal Research.Journal of Medical Ethics, o, pp. 1-4.

Luby, S.P., M. Agboatwalla, D.R. Feikin, J. Painter, W. Billhimer, A. Altaf and R.M. Hoekstra (2005). Effect of Handwashing on Child Health: A Randomized Controlled Trial. The Lancet, 366, pp. 225-233. 
Matthews, R.A. (2008). Medical progress depends on animal models - doesn't It? Journal of the Royal Society of Medicine, 101, pp. 95-98.

McManus, R. (2013). Ex-Director Zerhouni Surveys Value of NIH Research. NIH Record, LXV(13). [online] Available at:https://nihrecord.nih.gov/newsletters/2013/o6_21 _2013/storyı.htm [Accessed 30 January 2019].

NIH (2019). Budget. Research for the People. [online] Available at: https://www.nih. gov/about-nih/what-we-do/budget [Accessed on 3o January 2019].

Ormandy, E. and C. Schuppli (2014). Public Attitudes Toward Animal Research: A Review. Animals, 4, pp. 391-408.

Pippin, J.J. (2013). Animal Research in Medical Sciences: Seeking a Convergence of Science, Medicine, and Animal Law. South Texas Law Review, 54, pp. 469-511.

Plous, S. and H. Herzog (2001). Animal Research: Reliability of Protocol Reviews for Animal Research. Science, 293, pp. 6o8-6o9.

Pound, P. and M.B. Bracken (2014). Is Animal Research Sufficiently Evidence Based to Be a Cornerstone of Biomedical Research? British Medical Journal, 30, p. g3387.

Ramachandran, R. and S. Lisberger (2005). Normal Performance and Expression of Learning in the Vestibulo-Ocular Reflex (VOR) at High Frequencies. Journal of Neurophysiology, 4, pp. 2028-2038.

Roberts, W.A. (2012). Evidence for future-cognition in animals. Learning and Motivation, 43(4), pp. 169-180.

Schwagerl, C. and P. Crutzen (2014). The Anthropocene: The Human Era and How It Shapes Our Planet. Santa Fe: Synergetic Press.

Sung, N.S., W.F. Crowley Jr., M. Genel, P. Salber, L. Sandy, L.M. Sherwood, S.B. Johnson, H. Tilson; K. Getz, E.L. Larson, D. Scheinberg, E.A. Reece, H. Slavkin, A. Dobs, J. Grebb, R.A. Martinez, A. Korn and D. Rimoin (2003). Central Challenges Facing the National Clinical Research Enterprise. Journal of the American Medical Association, 289, pp. 1278-1287.

Swami, V., A. Furnham and A.N. Christopher (2008). Free the animals? Investigating attitudes toward animal testing in Britain and the United States. Scandinavian Journal of Psychology, 49, pp. 269-276.

Tsilidis, K.K., O.A. Panagiotou, E.S. Sena, E. Aretouli, E. Evangelou, D.W. Howells, S.R. Al-Shahi, M.R. Macleod and J.P. Ioannidis (2013). Evaluation of excess significance bias in animal studies of neurological diseases. PLoS Biology, 11, p. e10o16og.

Yartsev, M., R. Givon-Mayo, M. Maller and O. Donchin (2009). Pausing Purkinje Cells in the Cerebellum of the Awake Cat. Frontiers in Systems Neuroscience, 3(2), pp. 1-9. 